\title{
Mangiferin regulates proliferation and apoptosis in glioma cells by induction of microRNA-15b and inhibition of MMP-9 expression
}

\author{
JINSONG XIAO $^{1}$, LI LIU $^{1,2}$, ZIAN ZHONG $^{1,3}$, CHENG XIAO $^{1}$ and JUNJIAN ZHANG ${ }^{1}$ \\ ${ }^{1}$ Division of Neurology, Zhongnan Hospital of Wuhan University, Wuhan, Hubei 430071; \\ ${ }^{2}$ Division of Neurology, The Fifth People's Hospital of Chongqing, Xiangyang, Chongqing 400061; \\ ${ }^{3}$ Division of Neurology, Xiangyang City Hospital, Xiangyang, Hubei 441021, P.R. China
}

Received January 8, 2015; Accepted March 2, 2015

DOI: $10.3892 /$ or.2015.3919

\begin{abstract}
Mangiferin, a flavonoid extracted from the leaves of the Anacardiaceae plant, the mango tree, has physiological activity and pharmacological effects in many aspects. The present study aimed to clarify the effect of mangiferin on proliferation and apoptosis of glioma cells and the mechanism of these curative effects of mangiferin. In this experiment, we detected the proliferation using 3-(4,5-dimethylthylthiazol2-yl)-2,5 diphenyltetrazolium bromide (MTT) assay. Then, cell apoptosis of U87 glioma cells was measured with the Annexin V-FITC/propidium iodide (PI) apoptosis detection kit, DAPI staining assay and the caspase-3 and caspase-9 activity assay kit. Next, quantitative real-time PCR and gelatin zymography were used to analyze the expression of microRNA-15b (miR-15b) and matrix metalloproteinase-9 (MMP-9), respectively. MMP-9 agonist, miR-15b mimics and anti-miR-15b mimics were added to the U87 glioma cells for elucidating the mechanisms involved in the curative effects of mangiferin. In the present study, mangiferin notably restrained the proliferation and increased the apoptosis of the U87 glioma cells. Meanwhile, mangiferin specifically promoted the expression of miR-15b and suppressed the level of MMP-9 in the U87 glioma cells. miR-15b regulated the expression of MMP-9 in the U87 glioma cells. MMP-9 agonist and antimiR-15b reduced the curative effects of mangiferin in the U87 glioma cells. In summary, mangiferin regulates proliferation and apoptosis in glioma cells by induction of miR-15b and inhibition of MMP-9 expression.
\end{abstract}

\section{Introduction}

Glioma is the most common tumor among adults, with the highest degree of malignancy and the greatest lethality (1).

Correspondence to: Jinsong Xiao, Division of Neurology, Zhongnan Hospital of Wuhan University, Wuhan, Hubei 430071, P.R. China E-mail: jinsongxiaox@163.com

Key words: glioma, matrix metalloproteinase-9, mangiferin, microRNA-15b
Due to the heterogeneity and molecular abnormalities of glioma cells, the efficacy of current treatment options including surgery, radiotherapy and chemotherapy for glioma patients is not significant. In the past decade, the median survival of glioma patients has remained stable at 12 months or less (2). Previous studies on glioma mostly have focused on histopathology and molecular biology, and few have aimed at the systematic investigation of the correlation between tumor cell phenotype and the function nature in tumor tissue (3).

With developments in the field of molecular biology, studies have shown that microRNAs (miRs) play an important role in tumorigenesis and tumor development. An miR can downregulate the gene activity of cancer as a tumor suppressor, and can also downregulate gene activity as a cancer gene; it can regulate the expression of tumor-associated genes (4). The mutations, deletions, translocations and mutual regulation abnormalities can also lead to the abnormal expression levels of related genes. miR abnormalities are associated with cancer, and it has been found that hundreds of miRs are cancer-related. Suppression of miR-15b was found to result in an increase in the cell population of glioma cells in the $\mathrm{S}$ phase and a decrease in cell populations of glioma cells, while upregulation of miR-15b resulted in cell cycle arrest at the G0/G1 phase (5). Chung et al (6) reported that upregulation of miR-15b predicts a low risk of tumor recurrence of hepatocellular carcinoma.

The metalloproteinase family is a class of proteases that plays a key role in maintaining the stability of the cell microenvironment. Matrix metalloproteinases (MMPs) have the ability to cut each component of the extracellular matrix, such as collagen, laminin, fibronectin and proteoglycans (7). Matrix metalloproteinase-2 (MMP-2) and matrix metalloproteinase-9 (MMP-9) belong to the gelatinases, a class of metalloproteinases that are widely related and researched in the cancer field, both of which are capable of degrading type IV collagen, and the latter is the main component of the basement membrane (8). Both MMP-19 plays a key role in cancer metastasis and spread. Capsaicin suppresses the migration of cholangiocarcinoma cells by downregulating the MMP-9 expression signaling pathway (9). Recently Ma et al (10) illustrated that SUMO-specific protease 1 regulates the proliferation and invasion of pancreatic cancer cells through MMP-9. Park et al (11) illustrated that an ERK1/2 inhibitor 


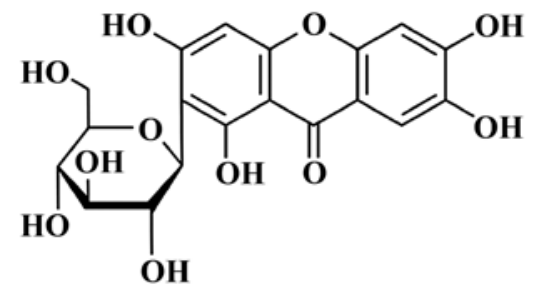

Figure 1. The chemical structure of mangiferin.

significantly inhibited proliferation of bladder cancer 5637 cells through suppression of MMP-9 expression.

Mangiferin, also named as mango element or chinonin, is a natural polyphenolic compound extracted from the liliaceous plant, Anemarrhena. Modern pharmacological and clinical studies have shown that mangiferin has physiological activity and pharmacological effects in many aspects (12). Mangiferin exhibits a significant central nervous system stimulant effect and a glucocorticoid-like anti-inflammatory effect, which can reduce capillary permeability, and its anti-inflammatory response rate is $38 \%$ (13). Mangiferin can block the cell cycle of human hepatoma cell line BEL-7404 at the G2/M phase, and we found in our previous study that mangiferin significantly inhibited the proliferation of the K562 chronic myeloid leukemia cell line (14). The finding that expression of miR-15b and MMP-9 were altered following mangiferin treatment can be the foundation for improved and more effective therapy for glioma. The aim of the present study was to uncover the molecular pathways involved in the effect of mangiferin on glioma cells.

\section{Materials and methods}

Reagents. The chemical structure of mangiferin (Sigma; with a purity $>98 \%$ ) is shown in Fig. 1. Dulbecco's modified Eagle's medium (DMEM) was purchased from Gibco (Carlsbad, CA, USA). Fetal bovine serum (FBS) was purchased from Invitrogen (Carlsbad, CA, USA). 3-(4,5-Dimethylthylthiazol2-yl)-2,5 diphenyltetrazolium bromide (MTT) was purchased from Nanjing KeyGen Biotech Co., Ltd. (Nanjing, China). Annexin V-FITC/propidium iodide (PI) apoptosis detection kit was purchased from BD Biosciences (San Jose, CA, USA). Caspase-3 and caspase- 9 activity assay kits were purchased from Tiangen Biotech (Beijing, China). BCA protein assay reagent was purchased from Shanghai Sangon Biotechnology (Shanghai, China). ABI 7300 HT sequence detection system was purchased from Applied Biosystems (Foster City, CA, USA).

Cell lines and cell culture. The human U87 glioma cell line was purchased from the Shanghai Cell Bank of Chinese Academy of Sciences (Shanghai, China). U87 cells were maintained in a $37^{\circ} \mathrm{C}, 5 \% \mathrm{CO}_{2}$ incubator in DMEM (Gibco) supplemented with $10 \%$ FBS (Invitrogen) containing $100 \mathrm{U} / \mathrm{ml}$ penicillin and $100 \mathrm{mg} / \mathrm{ml}$ streptomycin.

MTT assay. Human U87 glioma cells were seeded $\left(5 \times 10^{3}\right.$ cells/well) in 96-well plates for $24 \mathrm{~h}$. Cells of each well were treated with various doses of mangiferin $(25,50$ and $100 \mu \mathrm{M})$ (15) for 3 days. Subsequently, $50 \mu 1$ of MTT was added to each well and incubated at $37^{\circ} \mathrm{C}$ for an additional $4 \mathrm{~h}$. The supernatant was discarded, and $200 \mu \mathrm{l}$ dimethylsulfoxide was then added into each well to dissolve for $10 \mathrm{~min}$ at room temperature while being shaken. Optical density was measured at the wavelength of $570 \mathrm{~nm}$.

Apoptosis assay. Human U87 glioma cells were seeded (1x10 cells/well) in 6-well plates for $24 \mathrm{~h}$. Cells of each well were treated with various doses of mangiferin $(25,50$ and $100 \mu \mathrm{M})$ for 2 days. According to the manufacturer's instructions (BD Biosciences), the apoptotic cells were measured by the Annexin V-FITC/propidium iodide (PI) apoptosis detection kit. Annexin V-FITC (5 $\mu \mathrm{l})$ was added to each well and incubated at $37^{\circ} \mathrm{C}$ in the dark for $10 \mathrm{~min}$. Then, $5 \mu \mathrm{l}$ PI was added to each well, and cell apoptosis was analyzed by a Cytomics FC 500 flow cytometer.

DAPI staining assay. Human U87 glioma cells were seeded $\left(1 \times 10^{6}\right.$ cells/well) in 6 -well plates for $24 \mathrm{~h}$. Cells of each well were treated with various doses of mangiferin $(25,50$ and $100 \mu \mathrm{M}$ ) for 2 days. Cells were then stained with $1 \mu \mathrm{g} / \mathrm{ml}$ DAPI solution for $10 \mathrm{~min}$ at room temperature. Apoptotic cells were observed using a fluorescence microscope (Olympus Corp., Tokyo, Japan).

Caspase-3 and caspase-9 activation assay. Human U87 glioma cells were seeded $\left(5 \times 10^{3}\right.$ cells/well) in 96 -well plates for $24 \mathrm{~h}$. Cells of each well were treated with various doses of mangiferin $(25,50$ and $100 \mu \mathrm{M})$ for 2 days. In accordance with the manufacturer's instructions (Tiangen Biotech), caspase-3 and caspase- 9 activation was detected using caspase- 3 and caspase-9 activity assay kit. Cells were harvested and then incubated in ice-cold cell lysis buffer for $30 \mathrm{~min}$. The protein concentration was determined using the BCA protein assay reagent (Shanghai Sangon Biotechnology, Shanghai, China). Protein $(10 \mu \mathrm{l})$ was incubated with the relevant caspase substrate at $37^{\circ} \mathrm{C}$ for 4-6 h. Caspase- 3 and caspase- 9 activation was measured with a microplate spectrophotometer (Bio-Rad Laboratories, Hercules, CA, USA) at an absorbance of $405 \mathrm{~nm}$.

Quantitative real-time PCR ( $q R T$-PCR). Human U87 glioma cells were seeded $\left(1 \times 10^{6}\right.$ cells/well $)$ in 6 -well plates for $24 \mathrm{~h}$. Cells of each well were treated with various doses of mangiferin $(25,50$ and $100 \mu \mathrm{M})$ for 2 days. miR-15b expression of the cells was measured by qRT-PCR. Firstly, total RNA was extracted from the cells or transfected cells using TRIzol reagent (Invitrogen). Next, the relative level of miR-15b was detected by the ABI 7300 HT sequence detection system (Applied Biosystems, Foster, CA, USA) in cells or and transfected cells. miR-15b sequences were: 5'-GATACTCGAGCA GAAGTTTGGCTAATTTAATAATC-3' (forward) and 5'-GC GAATTCGCCAAGGATGACCTTAAGCCTC-3' (reverse). U6 sequences were: 5'-GCTTGCTTCGGCAGCACAT ATAC-3' (forward) and 5'-TGCATGTCATCCTTGCTCAG GG-3' (reverse). PCR cycles were as follows: $95^{\circ} \mathrm{C}$ for $10 \mathrm{~min}$, followed by 35 cycles of $95^{\circ} \mathrm{C}$ for $30 \mathrm{sec}, 58^{\circ} \mathrm{C}$ for $30 \mathrm{sec}$ and $72^{\circ} \mathrm{C}$ for $45 \mathrm{sec}$.

Gelatin zymography. Human U87 glioma cells were seeded ( $1 \times 10^{6}$ cells/well) in 6-well plates for $24 \mathrm{~h}$. Cells of each well 


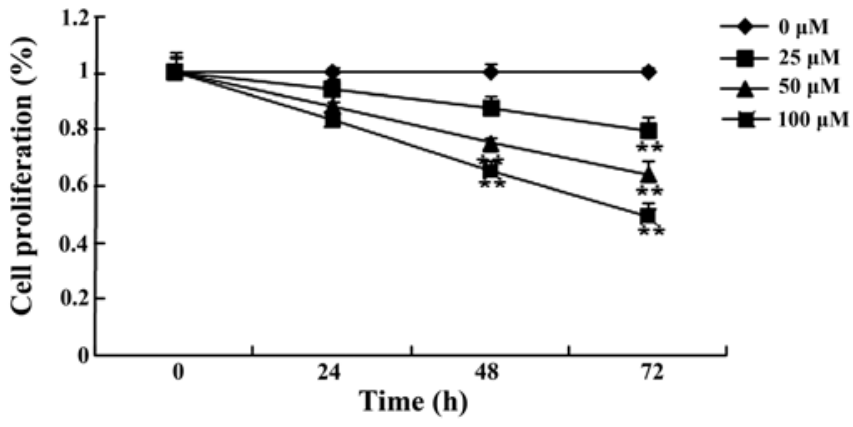

Figure 2. Mangiferin suppresses the proliferation of U87 glioma cells. ${ }^{* *} \mathrm{P}<0.01$ compared with the $0 \mu \mathrm{M}$ mangiferin treatment group.

were treated with various doses of mangiferin $(25,50$ and $100 \mu \mathrm{M}$ ) for 2 days. The culture supernatants were collected, and $20 \mu \mathrm{l}$ of collected media was added to an equal volume of sodium dodecylsulfate (SDS) sample buffer. Collected media were subjected to $10 \%$ polyacrylamide gel electrophoresis containing $1 \mathrm{mg} / \mathrm{ml}$ gelatin. After electrophoresis, the gels were washed twice with $2.5 \%$ Triton $\mathrm{X}-100\left(37^{\circ} \mathrm{C}\right.$ for $\left.15 \mathrm{~min}\right)$ and incubated in a reaction buffer at $37^{\circ} \mathrm{C}$ for $11-12 \mathrm{~h}$. After incubation, the gels were subsequently stained with $0.5 \%$ (w/v) Coomassie blue R-250 for $2 \mathrm{~h}$. Finally, Coomassie brilliant blue R-250 (Amresco, Solon, OH, USA) was used to stain the gels.

Cell transfection. miR-15b mimics and anti-miR-15b mimics were synthesized by Wuhan Genesil Biotechnology Co., Ltd. (Wuhan, China). Human U87 glioma cells were seeded $\left(1 \times 10^{6}\right.$ cells/well) in 6-well plates for $24 \mathrm{~h}$. In accordance with the manufacturer's instructions (Invitrogen), the mimics were allowed to transfect with Lipofectamine 2000 into the U87 glioma cells.
Statistical analysis. Data analysis was performed with SPSS 17.0 software and data are presented as means \pm SD. Differences were analyzed using one-way ANOVA. P-values of $<0.05$ were considered to indicate statistically significant results.

\section{Results}

Mangiferin suppresses the proliferation of U87 glioma cells. To explore the effect of mangiferin on the proliferation of U87 glioma cells, the cell growth viability was examined by MTT assay. As shown in Fig. 2, mangiferin (25, 50 and $100 \mu \mathrm{M}$ ) inhibited the proliferation of the U87 glioma cells in a time- and dose-dependent manner. Following treatment with mangiferin (50 and $100 \mu \mathrm{M}$ ) for 48 and $72 \mathrm{~h}$ and mangiferin $(25 \mu \mathrm{M})$ for $72 \mathrm{~h}$, the mangiferin-treated U87 glioma cells showed a significant decrease in proliferation relative to that of the $0 \mu \mathrm{M}$ mangiferin treatment group (Fig. 2).

Mangiferin induces apoptosis in the U87 glioma cells. To determine the effects of mangiferin on the apoptosis of U87 glioma cells, Annexin V-FITC/propidium iodide (PI) apoptosis detection kit and DAPI staining assay were employed to evaluate the cell apoptosis rate and caspase- 3 and caspase- 9 activation in the U87 glioma cells, respectively. As shown in Fig. 3A and B, mangiferin $(25,50$ and $100 \mu \mathrm{M})$ increased the cell apoptosis rate in a dose-dependent manner. Following treatment with mangiferin $(50$ and $100 \mu \mathrm{M})$ for $48 \mathrm{~h}$, the cell apoptosis rate was markedly increased, compared to that of the $0 \mu \mathrm{M}$ mangiferin treatment group (Fig. 3A and B). Meanwhile, the cell apoptosis was observed using DAPI staining assay. We found that the cell apoptosis rate was significantly increased following mangiferin treatment (25, 50 and $100 \mu \mathrm{M})$ (Fig. 3C).

Mangiferin induces caspase-3 and caspase-9 activation in the U87 glioma cells. To further elucidate the effects of
A
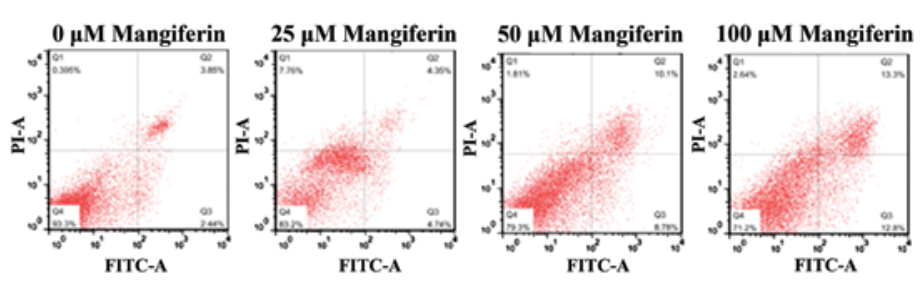

B

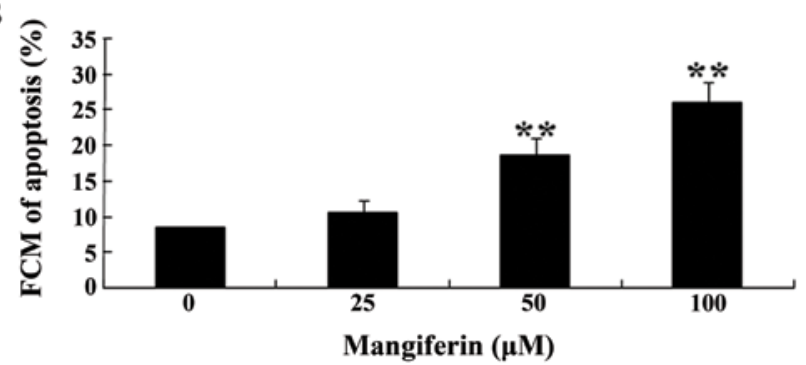

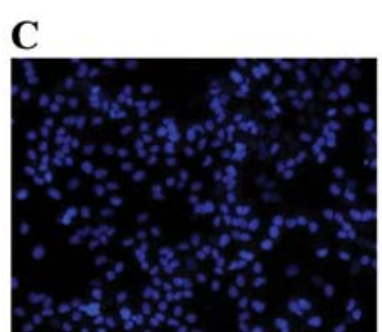

$\mathbf{0}$

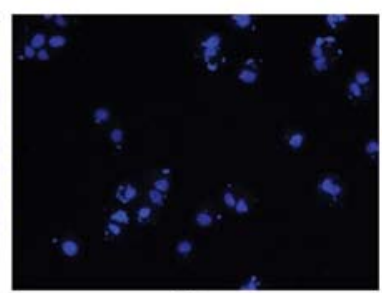

25

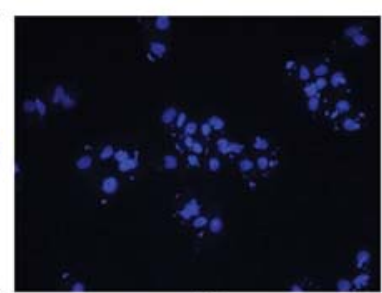

50

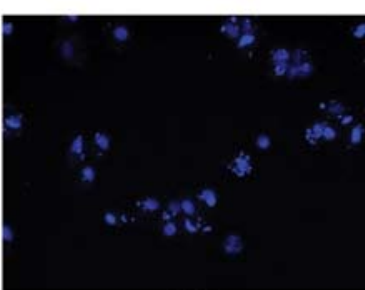

100

Mangiferin $(\mu \mathrm{M})$

Figure 3. Mangiferin induces the apoptosis of U87 glioma cells. (A) Flow cytometric analysis for detecting cellular apoptosis. (B) Statistical analysis of the cellular apoptosis levels. (C) DAPI staining assay for cellular apoptosis. ${ }^{* *} \mathrm{P}<0.01$ compared with the $0 \mu \mathrm{M}$ mangiferin treatment group. 

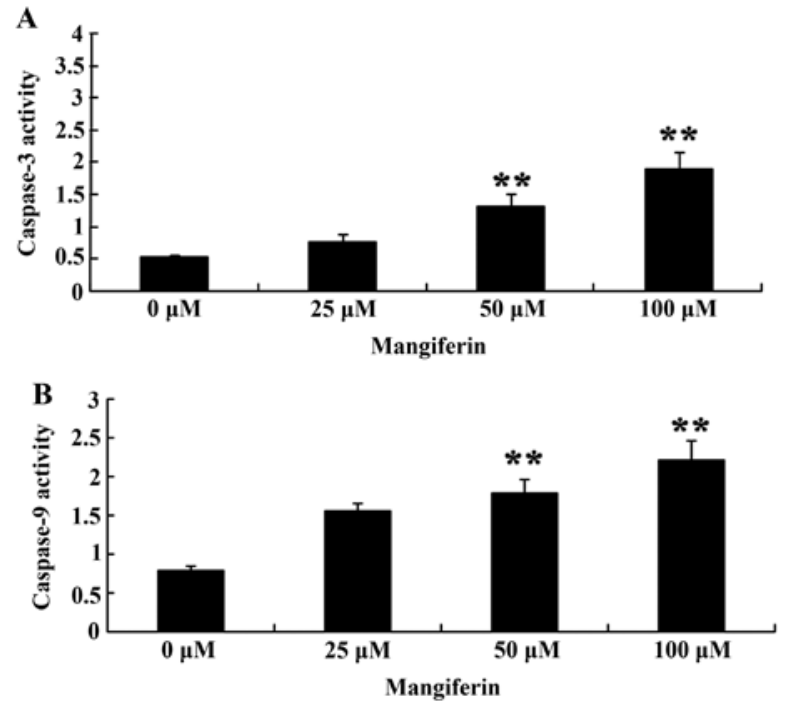

Figure 4. Mangiferin induces caspase-3 and caspase-9 activation in the U87 glioma cells. Mangiferin induced caspase-3 (A) and caspase-9 (B) activation in $\mathrm{U} 87$ glioma cells. ${ }^{* *} \mathrm{P}<0.01$ compared with the $0 \mu \mathrm{M}$ mangiferin treatment group.

mangiferin on caspase-3 and caspase-9 activation in the U87 glioma cells, caspase- 3 and caspase- 9 activation was estimated using activity assay kits. Caspase- 3 and caspase- 9 activation was also markedly increased following the treatment of mangiferin $(50$ and $100 \mu \mathrm{M})$ for $48 \mathrm{~h}$ in comparison to that of the $0 \mu \mathrm{M}$ mangiferin treatment group (Fig. 4).

Mangiferin promotes miR-15b expression in the U87 glioma cells. To evaluate whether mangiferin promotes miR-15b expression, we used qRT-PCR to analyze miR-15b expression in the U87 glioma cells. The expression of miR-15b in the U87 glioma cells was markedly increased, following the treatment of mangiferin (50 and $100 \mu \mathrm{M}$ ) for $48 \mathrm{~h}$ (Fig. 5).

Mangiferin suppresses MMP-9 expression in the U87 glioma cells. We estimated the expression of MMP-9 following the treatment of mangiferin in the U87 glioma cells. Following treatment with mangiferin (50 and $100 \mu \mathrm{M})$ for $48 \mathrm{~h}$, the results of the gelatin zymography assay revealed that the expression of MMP-9 in the U87 glioma cells was markedly suppressed in comparison to that of the $0 \mu \mathrm{M}$ mangiferin treatment group (Fig. 6).

MMP-9 agonist restrains the effect of mangiferin on U87 glioma cells. The relationship of MMP-9 expression and the effect of mangiferin on U87 glioma cells was detected. Following treatment with mangiferin $(50 \mu \mathrm{M})$ for $48 \mathrm{~h}$, the MMP-9 agonist (P-aminophenylmercuric acetate, $1 \mathrm{mM}$ ) significantly increased the MMP-9 expression in the U87 glioma cells in comparison to that of the $0 \mu \mathrm{M}$ mangiferin group (Fig. 7A and B). Next, the MMP-9 agonist reversed the effect of mangiferin on cell proliferation and the caspase-3 activation in the U87 glioma cells (Fig. 7C and D).

Overexpression of miR-15b and expression of MMP-9 in the U87 glioma cells. To investigate the association between the overexpression of miR-15b and expression of MMP-9 in the

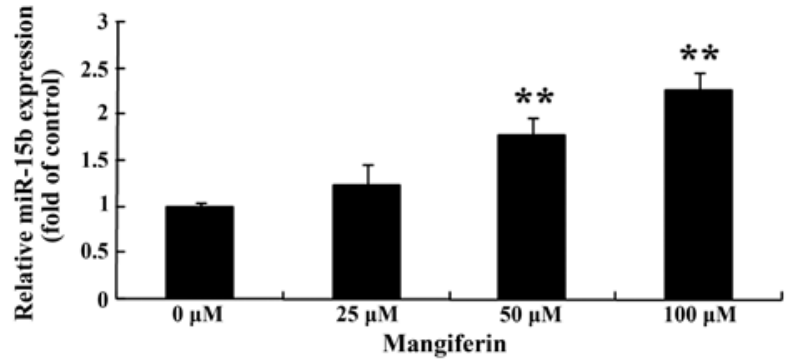

Figure 5. Mangiferin promotes miR-15b expression in U87 glioma cells. ${ }^{* *} \mathrm{P}<0.01$ compared with the $0 \mu \mathrm{M}$ mangiferin treatment group.

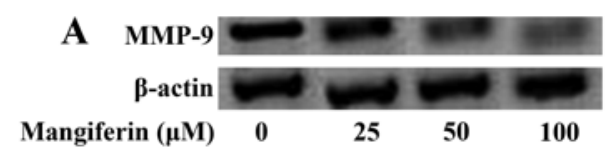

B

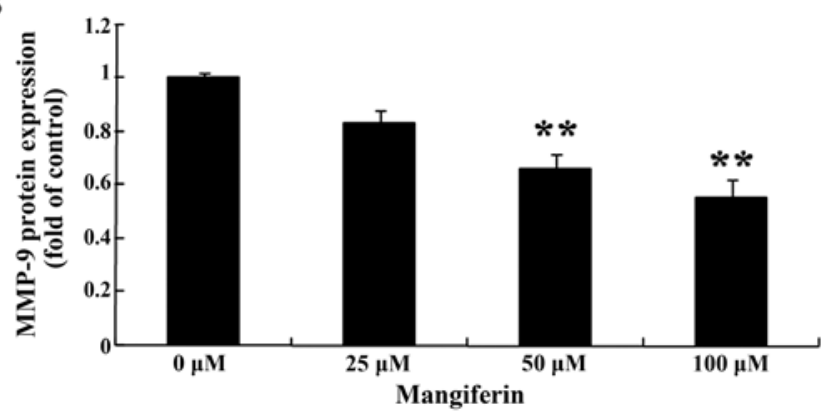

Figure 6. Mangiferin suppresses MMP-9 expression in the U87 glioma cells. Representative gelatin zymography analysis of (A) MMP-9 expression. (B) Statistical analysis of MMP-9 expression. ${ }^{* *} \mathrm{P}<0.01$ compared with the $0 \mu \mathrm{M}$ mangiferin treatment group.

U87 glioma cells, miR-15b mimics were transfected into the U87 glioma cells and the expression levels of miR-15b and MMP-9 were measured with qRT-PCR and gelatin zymography assay, respectively. Firstly, miR-15b mimics markedly increased the expression of miR-15b in the U87 glioma cells, compared to that in the control group (Fig. 8A). Next, miR-15b mimics also reduced the expression MMP-9 in the U87 glioma cells, compared to that of the control group (Fig. 8B).

Anti-miR-15b and the effect of mangiferin. We further determine the correlations of miR- $15 \mathrm{~b}$ expression level and the effect of mangiferin on glioma cells. Firstly, anti-miR-15b mimics were transfected into the U87 glioma cells. Lower expression of miR-15b was observed in the transfected cells (Fig. 9A). Similarly, anti-miR-15b mimics meaningfully reversed the effect of mangiferin $(50 \mu \mathrm{M})$ on cell proliferation (Fig. 9B) and apoptosis of U87 glioma cells (Fig. 9C) at $48 \mathrm{~h}$. Meanwhile, anti-miR-15b mimics also accelerated the levels of MMP-9 in the U87 glioma cells (Fig. 9D).

\section{Discussion}

Uncontrolled proliferation and high invasive ability, the most typical malignant phenotypes of malignant glioma, limit the ability to cure this cancer. The main reason for the failure of the clinical treatment of malignant glioma is the uncontrolled 
A

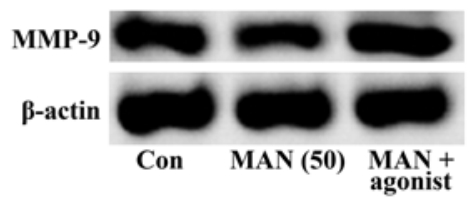

B
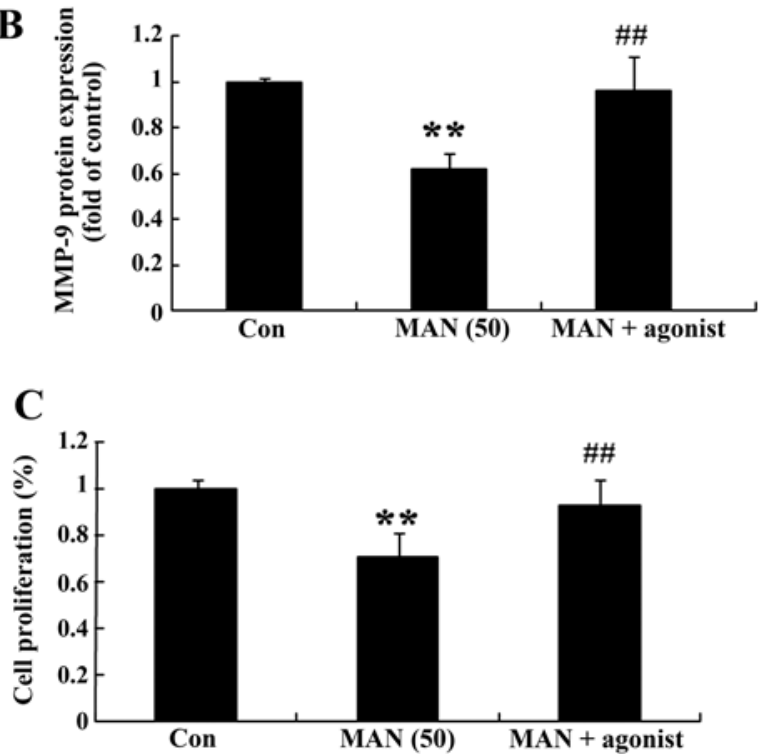

D

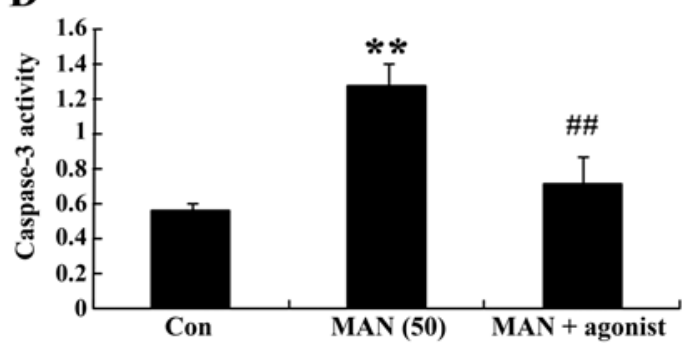

Figure 7. MMP-9 agonist suppresses the effect of mangiferin on U87 glioma cells. (A and B) Representative gelatin zymography analysis of MMP-9 expression. Mangiferin inhibits (C) cell proliferation and (D) caspase-3 activation in the U87 glioma cells. ${ }^{* *} \mathrm{P}<0.01$ compared with the $0 \mu \mathrm{M}$ mangiferin treatment group, ${ }^{\# \#} \mathrm{P}>0.05$ compared with the $50 \mu \mathrm{M}$ mangiferin treatment group. Con, control group; MAN (50), mangiferin $(50 \mu \mathrm{M})$ treatment group; MAN + agonist, mangiferin $(50 \mu \mathrm{M})+$ MMP-9 agonist $(1 \mathrm{mM})$.

proliferation and invasive growth (16). In the present study, our data revealed that mangiferin suppressed the proliferation of U87 glioma cells. Mangiferin was previously found to inhibit human nasopharyngeal carcinoma cell proliferation by Bcl-2 and Bax expression (15). Meanwhile, we found that mangiferin induced the cell apoptosis rate and increased the activation of caspase- 3 and caspase-9 in U87 glioma cells. García-Rivera et al (17) indicated that the antitumor effects of mangiferin were through increased apoptosis in MDA-MB231 breast cancer cells. du Plessis-Stoman et al (18) illustrated that combination treatment with oxaliplatin and mangiferin accelerated apoptosis through inhibition of NF- $\mathrm{BB}$ in cancer cell lines.

miRNAs play an important role in normal growth and development, proliferation, differentiation and apoptosis of cells (19). miRNAs are mainly involved in the regulation of

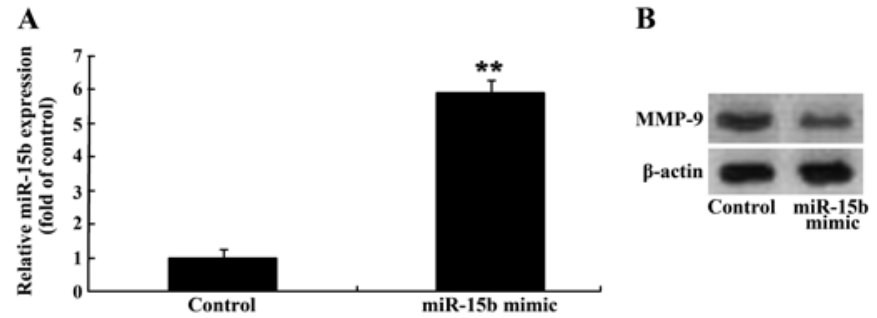

Figure 8. Overexpression of miR-15b and expression of MMP-9 in the U87 glioma cells. Overexpression of miR-15b increased (A) the expression of miR-15b and (B) inhibited MMP-9 expression. ${ }^{* *} \mathrm{P}<0.01$ compared with the $0 \mu \mathrm{M}$ mangiferin treatment group.

A
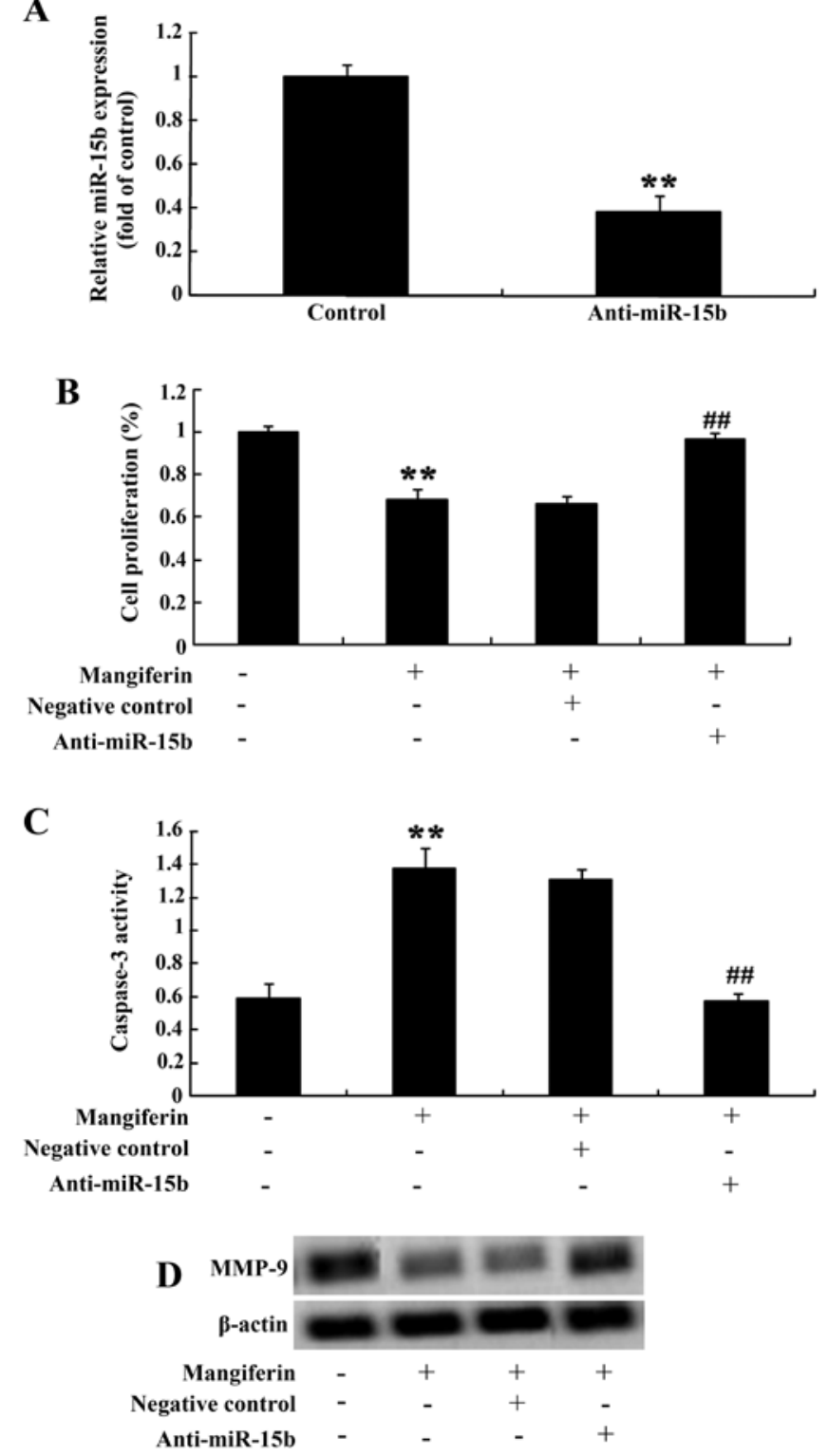

Figure 9. Anti-miR-15b and the effect of mangiferin. (A) Anti-miR-15b reversed the effect of mangiferin on the expression of miR-15b in U87 glioma cells. (B) After treatment with mangiferin $(50 \mu \mathrm{M})$ for $48 \mathrm{~h}$, anti-miR-15b significantly promoted the cell proliferation of U87 glioma cells. (C) After treatment with mangiferin $(50 \mu \mathrm{M})$ for $48 \mathrm{~h}$, anti-miR-15b evidently inhibited cell apoptosis of U87 glioma cells. (D) Anti-miR-15b significantly increased the expression of MMP-9 expression in U87 glioma cells after mangiferin $(50 \mu \mathrm{M})$ treatment at $48 \mathrm{~h} .{ }^{* * *} \mathrm{P}<0.01$ compared with the $0 \mu \mathrm{M}$ mangiferin treatment group and ${ }^{\# \#} \mathrm{P}<0.01$ compared with the mangiferin-treatment group transfected with negative control. 
genes related to cell fate, especially in the development-related genes; however, almost no relevant genes that maintain the basic activities of cells have miRNA target sites (20). In the present study, we found that mangiferin specifically increased the expression of miR-15b in the U87 glioma cells.

Among the metalloproteinase family members, the gelatinases MMP-2 and MMP-9 have been 'hot topics' of research (21). According to reports, MMP2 expression is increased in a variety of cancers, including lung cancer and the prognosis is poor. In addition, our findings showed that the expression of MMP-9 in U87 glioma cells was controlled by the treatment of mangiferin. Meanwhile, Kim et al (22) reported that mangiferin exerts anti-photoaging activity by regulating MMP-9 expression through inhibition of mitogen-activated protein kinase kinase 1 and extracellular signal-regulated kinase. In PMA-stimulated human astroglioma cells, mangiferin inhibited MMP-9 gene expression through the PI3K/Akt and MAPK signaling pathways (23). However, we found that the MMP-9 agonist reversed the effect of mangiferin on U87 glioma cells.

In the present study, we demonstrated that overexpression of miR-15b in U87 glioma cells suppressed the expression level of MMP-9. In contrast, downregulation of miR-15b reversed the effect of mangiferin in the U87 glioma cells. Zheng et al (24) reported that miR-15b deactivated the MEK-ERK pathway through MMP-3 in 9L glioma cells. Sun et al (25) suggested that treatment of gastric cancer cells increased miR-15b expression corresponding with downregulation of MMP-9 and MMP-2.

In summary, this is the first report that mangiferin regulates proliferation and apoptosis in glioma cells by inhibiting the expression of MMP-9 and by inactivating the expression of miR-15b. The different signaling pathways indicated in the present study may help us elucidate the anticancer effects of mangiferin, also aiding in the knowledge of possible drug resistance mechanisms.

\section{References}

1. Pan WR, Li G and Guan JH: Polymorphisms in DNA repair genes and susceptibility to glioma in a Chinese population. Int $\mathrm{J}$ Mol Sci 14: 3314-3324, 2013.

2. Liu X, Wang L, Chen J, Ling Q, Wang H, Li S, Li L, Yang S, $\mathrm{Xia} \mathrm{M}$ and Jing L: Estrogen receptor beta agonist enhances temozolomide sensitivity of glioma cells by inhibiting PI3K/ AKT/mTOR pathway. Mol Med Rep 11: 1516-1522, 2014.

3. Jovcevska I, Kocevar N and Komel R: Glioma and glioblastoma - how much do we (not) know? Mol Clin Oncol 1: 935-941, 2013.

4. Guo X, Xia J and Yan J: Promoter methylated microRNAs: Potential therapeutic targets in gastric cancer (Review). Mol Med Rep 1: 759-765, 2014.

5. Xia H, Qi Y, Ng SS, Chen X, Chen S, Fang M, Li D, Zhao Y, $\mathrm{Ge} \mathrm{R}, \mathrm{Li} \mathrm{G}$, et al: MicroRNA-15b regulates cell cycle progression by targeting cyclins in glioma cells. Biochem Biophys Res Commun 380: 205-210, 2009.

6. Chung GE, Yoon JH, Myung SJ, Lee JH, Lee SH, Lee SM, Kim SJ, Hwang SY, Lee HS and Kim CY: High expression of microRNA-15b predicts a low risk of tumor recurrence following curative resection of hepatocellular carcinoma. Oncol Rep 23: 113-119, 2010.
7. Heo W, Lee YS, Son CH, Yang K, Park YS and Bae J: Radiation-induced matrix metalloproteinases limit natural killer cell-mediated anticancer immunity in NCI-H23 lung cancer cells. Mol Med Rep 11: 1800-1806, 2014.

8. Cheng X, Gu J, Zhang M, Yuan J, Zhao B, Jiang J and Jia X: Astragaloside IV inhibits migration and invasion in human lung cancer A549 cells via regulating PKC-alpha-ERK1/2-NFkappaB pathway. Int Immunopharmacol 23: 304-313, 2014.

9. Lee GR, Jang SH, Kim CJ, Kim AR, Yoon DJ, Park NH and Han IS: Capsaicin suppresses the migration of cholangiocarcinoma cells by down-regulating matrix metalloproteinase- 9 expression via the AMPK-NF-kappaB signaling pathway. Clin Exp Metastasis 31: 897-907 2014.

10. Ma C, Wu B, Huang X, Yuan Z, Nong K, Dong B, Bai Y, Zhu H, Wang W and Ai K: SUMO-specific protease 1 regulates pancreatic cancer cell proliferation and invasion by targeting MMP-9. Tumour Biol 35: 12729-12735, 2014.

11. Park SL, Won SY, Song JH, Kim WJ and Moon SK: EPO gene expression induces the proliferation, migration and invasion of bladder cancer cells through the p21WAF1-mediated ERK1/2/ NF-к/MMP-9 pathway. Oncol Rep 32: 2207-2214, 2014.

12. Zhang B, Zhao J, Li S, Zeng L, Chen Y and Fang J: Mangiferin activates the Nrf2-ARE pathway and reduces etoposide-induced DNA damage in human umbilical cord mononuclear blood cells Pharm Biol 53: 503-511, 2014.

13. Xiao W, Hou J, Ma J, Yu B, Ren J, Jin W, Wu J, Zheng D and Fan K: Mangiferin loaded magnetic PCEC microspheres: preparation, characterization and antitumor activity studies in vitro. Arch Pharm Res: Sep 30, 2014 (Epub ahead of print).

14. Hu XY, Deng JG, Wang L and Yuan YF: Synthesis and antitumor activity evaluation of gallic acid-mangiferin hybrid molecule. Med Chem 9: 1058-1062, 2013.

15. Pan LL, Wang AY, Huang YQ, Luo Y and Ling M: Mangiferin induces apoptosis by regulating $\mathrm{Bcl}-2$ and $\mathrm{Bax}$ expression in the CNE2 nasopharyngeal carcinoma cell line. Asian Pac J Cancer Prev 15: 7065-7068, 2014.

16. Ma H, Zhang Y, Wang H, Han C, Lei R, Zhang L, Yang Z, Rao L, Qing $\mathrm{H}$ and Xiang J: Effect and mechanism of mitomycin $\mathrm{C}$ combined with recombinant adeno-associated virus type II against glioma. Int J Mol Sci 15: 1-14, 2014

17. García-Rivera D, Delgado R, Bougarne N, Haegeman G and Berghe WV: Gallic acid indanone and mangiferin xanthone are strong determinants of immunosuppressive anti-tumour effects of Mangifera indica L. bark in MDA-MB231 breast cancer cells. Cancer Lett 305: 21-31, 2011

18. du Plessis-Stoman D, du Preez J and van de Venter M: Combination treatment with oxaliplatin and mangiferin causes increased apoptosis and downregulation of NFkappaB in cancer cell lines. Afr J Tradit Complement Altern Med 8: 177-184, 2011.

19. Yang O, Huang J and Lin S: Regulatory effects of miRNA on gastric cancer cells. Oncol Lett 8: 651-656, 2014.

20. Kavitha N, Vijayarathna S, Jothy SL, Oon CE, Chen Y, Kanwar JR and Sasidharan S: MicroRNAs: biogenesis, roles for carcinogenesis and as potential biomarkers for cancer diagnosis and prognosis. Asian Pac J Cancer Prev 15: 7489-7497, 2014.

21. Zhu Y, Zhu L, Lu L, Zhang L, Zhang G, Wang Q and Yang P: Role and mechanism of the alkylglycerone phosphate synthase in suppressing the invasion potential of human glioma and hepatic carcinoma cells in vitro. Oncol Rep 32: 431-436, 2014.

22. Kim HS, Song JH, Youn UJ, Hyun JW, Jeong WS, Lee MY, Choi HJ, Lee HK and Chae S: Inhibition of UVB-induced wrinkle formation and MMP-9 expression by mangiferin isolated from Anemarrhena asphodeloides. Eur J Pharmacol 689: 38-44, 2012.

23. Jung JS, Jung K, Kim DH and Kim HS: Selective inhibition of MMP-9 gene expression by mangiferin in PMA-stimulated human astroglioma cells: involvement of PI3K/Akt and MAPK signaling pathways. Pharmacol Res 66: 95-103, 2012.

24. Zheng X, Chopp M, Lu Y, Buller B and Jiang F: MiR-15b and miR-152 reduce glioma cell invasion and angiogenesis via NRP-2 and MMP-3. Cancer Lett 329: 146-154, 2013.

25. Sun H, Meng X, Han J, Zhang Z, Wang B, Bai X and Zhang X: Anti-cancer activity of DHA on gastric cancer - an in vitro and in vivo study. Tumour Biol 34: 3791-3800, 2013. 